\title{
Sex differences in obstructive sleep apnoea in an elderly French population
}

\author{
E. Sforza*, F. Chouchou*, P. Collet ${ }^{\#}$, V. Pichot*, J.C. Barthélémy* and F. Roche*
}

ABSTRACT: Obstructive sleep apnoea (OSA) affects females and males differently, and increases in prevalence with age. The aim of the present study was to characterise clinical, anthropometric and polygraphic sex differences in a large elderly OSA population.

A total of 641 subjects aged 68 yrs were examined. Measurements of fat mass, using dualenergy X-ray absorptiometry (DEXA) and polygraphy, were obtained in all subjects. An apnoea/ hypopnoea index $(\mathrm{AHI})$ of $>15$ events $\cdot \mathrm{h}^{-1}$ identified the presence of OSA.

OSA was diagnosed in $57 \%$ of the sample, $34 \%$ having a mild form and $23 \%$ having an $\mathrm{AHI}$ of $>30$ events $\cdot h^{-1}$. Females with OSA exhibited a lower AHI, less severe hypoxaemia and greater peripheral fat mass, and frequently reported anxiety and depression. Comparison of females with and without OSA did not reveal significant differences in clinical, anthropometric and DEXA data. After adjustment for body mass index, hypertension, diabetes, smoking, anxiety and depression, logistic regression analysis revealed that the presence of hypertension was significantly associated with OSA risk in females (OR 1.52, $p=0.04$ ).

In a general community healthy population, the prevalence of undiagnosed OSA in females increases with age, with a risk similar to that in males. In females, the clinical spectrum, anthropometric data and fat distribution appear to be more sex-related than OSA-dependent. The occurrence of OSA contributes to hypertensive risk in elderly females.

KEYWORDS: Elderly, hypertension, obesity, sex, sleep apnoea, symptoms

A ccording to epidemiological studies on obstructive sleep apnoea (OSA) prevalence, ageing and sex substantially affect the incidence of the disorder, with rates rising from $<15 \%$ in middle-aged adults [1] to $24-38 \%$ in older adults $[2,3]$. Sex seems to affect the incidence of the disease, OSA being more prevalent in males than in females [4,5], with a male:female ratio of 8-10:1 or greater in clinical studies, and approximately $2: 1$ or $3: 1$ in epidemiological studies. The reason for the reduced susceptibility to OSA in females is not entirely clear, and many factors have been evoked, such as body fat distribution [6], upper airways shape [7], craniofacial morphology [8] and hormonal influences [9-11]. Females with OSA are less likely to show the classic symptoms of OSA, such as snoring and apnoea, and they report sleepiness less frequently and fatigue, depression and anxiety more frequently [12], and have a lower apnoea/hypopnoea index (AHI), frequently confined to rapid eye movement sleep [13]. Therefore, OSA may be underdiagnosed in females due to a different clinical profile. Concerning the cardiovascular consequences, results are controversial, with some authors reporting a greater incidence in males [14] and others reporting similar data between sexes $[15,16]$.

Since OSA in older adults may not have the same functional consequences as seen in middle-aged adults [17-20], it is interesting to determine whether, even in elderly subjects, some factors differentiate males and females with OSA.

The objectives of the present study were to examine the sex differences in sleep-related symptoms, sleepiness, mood disorders, fat distribution and cardiovascular risk in a large cohort of community-dwelling elderly persons aged $<70$ yrs and having OSA. The age-matched population, the high proportion of females and the extensive examination, as well as the presence of a non-OSA sample, permitted assessment of whether, in older females, clinical and anthropometric differences are related more to sex characteristics rather than to OSA.

\section{METHODS}

\section{Subjects}

Subjects for the present study were selected from the participants of the PROgnostic indicator OF cardiovascular and cerebrovascular events

\section{AFFILIATIONS}

*Service de Physiologie Clinique et de l'Exercice, Centre Hospitalier Universitaire Nord, Saint-Etienne, Faculté de Médecine Jacques Lisfranc, and

\#Service de Rhumatologie, Centre Hospitalier Universitaire de SaintEtienne, Faculté de Médecine Jacques Lisfranc, Université Jean Monnet, Saint-Etienne, France.

CORRESPONDENCE

E. Sforza

Service de Physiologie Clinique EFCR

Centre Hospitalier Universitaire Nord Niveau 6

F-42055 Saint-Etienne Cedex 2 France

E-mail: e.sforza@yahoo.fr

Received:

March 182010

Accepted after revision:

Aug 102010

First published online:

Sept 302010 
(PROOF) study [21], a prospective cohort study of 1,011 community-dwellers with a mean \pm SEM age of $65 \pm 2.0 \mathrm{yrs}$, randomly recruited from the electoral lists of the city of SaintEtienne (France). An ancillary study addressing the association between OSA, assessed by an at-home polygraphic study, and cardiovascular and cerebrovascular morbidity during a 7-yr follow-up was proposed to participants (Autonomic Nervous System Activity, Aging and Sleep Apnea/Hypopnea (SYNAPSE) study). Of the original sample of 1,011, 851 subjects participated in the SYNAPSE study. When compared to those who refused polygraphy, the final sample did not differ in any variables, including educational level, sex, daytime sleepiness and incidence of prior disease. From this sample, 641 subjects, aged $68.5 \pm 0.06$ yrs, who had undergone a complete evaluation, including clinical interview, anthropometric measurements, 24-h blood pressure measurement, polygraphy and body composition analysis using dual-energy X-ray absorptiometry (DEXA), were included in the current study. None of the female subjects examined were taking hormone replacement therapy.

The study was approved by the local ethics committee (Consultative Committee for the Protection of Persons participating in Biomedical Research (CCPPRB) Rhône-Alpes Loire, Saint-Etienne, France), and written informed consent to participation was obtained from all individuals.

\section{Clinical assessment}

The detailed clinical assessment focused on cardiac and cerebrovascular disease, hypertension (HTN), diabetes, and respiratory, neurological and psychiatric disorders. Current medication was analysed with regard to antihypertensive, hypnotic, anxiolytic and/or antidepressant therapy. Subjects were defined as normotensive if they did not report a history of HTN and antihypertensive treatment, and did not have a mean systolic blood pressure of $>135 \mathrm{mmHg}$ and a mean diastolic blood pressure of $>85 \mathrm{mmHg}$ during the ambulatory blood pressure monitoring.

\section{Anthropometric and DEXA measurements}

Body mass index (BMI) was calculated as weight (in kilograms) divided by height (in metres) squared. Neck circumference (NC) was measured in the midway of the neck between the mid-cervical spine and the mid-anterior neck to $0.5 \mathrm{~cm}$ below the laryngeal prominence. Waist circumference (WC) was measured midway between the lower rib margin and the iliac crest, and hip circumference (HC) was measured at the level of the two bony prominences in front of the hips.

Regional (arms, legs, trunk and head) body fat and lean body mass were measured using a whole-body DEXA scanner (Hologic QDR-2000; Hologic Inc., Bedford, MA, USA) within 4 months after polygraphy. Standard procedures for DEXA measurement were applied [22]. Peripheral fat mass (PFM) was calculated by adding the fat mass of the legs to that of the arms, and central fat mass (CFM) was calculated by adding the fat mass of the trunk to that of the head.

\section{Questionnaires}

Depressive symptoms were assessed using the shortened form of the Questionnaire of Self-Evaluated Depressive Symptomatology (QD2A) [23], and subjects with a score of $>6$ were considered as having depressive symptoms. Anxiety was assessed using the French version of the Goldberg scale, individuals with a score of $>4$ being considered anxious [24].

The impact of sleepiness was evaluated using the Epworth Sleepiness Scale (ESS) [25], and excessive daytime sleepiness was assessed by a score of $\geqslant 10$.

The Berlin Questionnaire has been proposed to screen for OSA in the general population [26]. Patients were considered to be at high risk if they gave a positive response to at least two of the following three criteria: 1) persistent symptoms for at least two snoring questions, 2) persistent somnolence during the daytime and/or while driving (>3 times $\cdot$ week $\left.^{-1}\right)$, and 3) a history of HTN or a BMI of $>30 \mathrm{~kg} \cdot \mathrm{m}^{-2}$.

All questionnaires were administered at the time of the sleep study.

\section{Sleep study}

A nocturnal unattended home-sleep study was performed in all subjects using a polygraphic system (HypnoPTT; Tyco Healthcare, Puritan Bennett, Boulder, CO, USA), which measured the following parameters: sound, electrocardiography, pulse transit time, R-R timing, airflow by nasal pressure, thoracoabdominal respiratory efforts by inductance plethysmography and body position. Arterial oxygen saturation $\left(\mathrm{Sa}, \mathrm{O}_{2}\right)$ was measured by pulse oximetry. A software package was used for downloading the tracings, and all of the recordings were visually validated and manually scored for respiratory events and nocturnal $\mathrm{Sa}_{2} \mathrm{O}_{2}$, with an intra-scorer reliability of $88 \%$. A recording was considered acceptable if $\geqslant 5 \mathrm{~h}$ of recording without missing data for respiratory signals or $\mathrm{Sa}_{1} \mathrm{O}_{2}$ was obtained. A second night of monitoring was performed when subjective sleep latency was $>2 \mathrm{~h}$ on the first night, sleep duration was $<5 \mathrm{~h}$ or the respiratory recording was not considered acceptable. Scoring was carried out following the standard criteria proposed for polygraphy [27]. Hypopnoea was defined as a $\geqslant 50 \%$ reduction in airflow lasting for $\geqslant 10 \mathrm{~s}$ and associated with $\geqslant 3 \%$ oxygen desaturation. Apnoeas were defined as the absence of airflow on the nasal cannula lasting $>10 \mathrm{~s}$. The AHI was established as the number of apnoeas plus hypopnoeas per hour of recording. The following were used as indices of nocturnal hypoxaemia: mean $\mathrm{Sa}_{2} \mathrm{O}_{2}$, percentage of recording time with an $\mathrm{Sa}_{1} \mathrm{O}_{2}$ of $<90 \%$, minimal $\mathrm{Sa}_{1} \mathrm{O}_{2}$ and oxygen desaturation index (ODI) i.e. the number of oxygen desaturations of $\geqslant 3 \%$ per hour of recording time. Using pulse transit time [28], an autonomic respiratory-related and total arousal index was calculated. An AHI of $>15$ events $\cdot \mathrm{h}^{-1}$ with $\geqslant 50 \%$ of events scored as obstructive was considered diagnostic of OSA [29]. Cases were stratified as mild (AHI of $>15$ events $\cdot h^{-1}$ but $<30$ events $\cdot h^{-1}$ ) and moderate-to-severe $\left(\mathrm{AHI}>30\right.$ events $\left.\cdot \mathrm{h}^{-1}\right)$.

\section{Statistical analyses}

Subjects' characteristics were summarised as mean \pm SEM for continuous variables, and counts and percentages for categorical variables. The groups were compared using an unpaired t-test for variables measured on a continuous scale, and, where appropriate, one-way ANOVA with post hoc Scheffé comparison. 
Logistic regression analysis was used to examine the effect of clinical and anthropometric parameters on sex with adjustment for the covariates, such as HTN, diabetes, dyslipidaemia, anxiety, depression, smoking, BMI and AHI. All statistical analyses were conducted using the SPSS statistical software package (SPSS for Windows, version 12.0; SPSS, Inc., Chicago, IL, USA). After Bonferroni correction, statistical significance was taken at $\mathrm{p}<0.05$.

\section{RESULTS}

\section{General sample}

A total of 379 females and 262 males (table 1) were analysed. Compared to males, females exhibited a lower BMI and NC and more frequently reported being diagnosed and treated for hyperlipidaemia, anxiety and depression. Males reported being smokers and diabetic more frequently. The prevalence of HTN was $42.6 \%$, similar in both sexes.

An AHI of $>15$ events $\cdot h^{-1}$ was identified in 369 (57\%) subjects, with $34 \%$ having a mild form and $24 \%$ having an $\mathrm{AHI}$ of $>30$ events $\cdot h^{-1}$ (table 2). A significant increase in the odds ratio for an AHI of $>30$ events $\cdot h^{-1}$ was found in males (OR 3.02, 95\% CI $2.00-4.56 ; \mathrm{p}<0.001), 33 \%$ of males being at greater risk of having an AHI of $>30$ events $\cdot \mathrm{h}^{-1}$ (females $16.6 \%$ ).

\section{Differences between females and males with OSA}

Within the group with an AHI of $>15$ events $\cdot h^{-1}$ (table 2 ), past history revealed a high percentage of females with hyperlipidaemia and intake of antidepressants and benzodiazepines. Females more frequently did not report snoring and apnoea at the first item of the Berlin questionnaire $(p=0.005)$, they perceived themselves to be less sleepy on the ESS, and more

\begin{tabular}{|c|c|c|c|}
\hline & Males & Females & p-value ${ }^{\#}$ \\
\hline Subjects n (\%) & $262(40.9)$ & $379(59.1)$ & \\
\hline Age yrs & $68.5 \pm 0.05$ & $68.6 \pm 0.04$ & NS \\
\hline BMI $\mathbf{k g} \cdot \mathbf{m}^{-2}$ & $26.1 \pm 0.2$ & $24.8 \pm 0.2$ & $<0.001$ \\
\hline Neck circumference $\mathrm{cm}$ & $40.3 \pm 0.2$ & $34.4 \pm 0.1$ & $<0.001$ \\
\hline Ambulatory SBP mmHg & $121.1 \pm 0.98$ & $116.8 \pm 0.7$ & NS \\
\hline Ambulatory DBP $\mathrm{mmHg}$ & $76.6 \pm 0.4$ & $72.6 \pm 0.4$ & NS \\
\hline \multicolumn{4}{|l|}{ Clinical data } \\
\hline Hypertension & 45.4 & 40.6 & NS \\
\hline Diabetes & 9.1 & 3.4 & 0.002 \\
\hline Dyslipidaemia & 29.4 & 38.5 & 0.01 \\
\hline Smoker & 43.9 & 12.7 & $<0.001$ \\
\hline Hypnotic treatment & 1.1 & 2.4 & NS \\
\hline Antidepressant treatment & 2.3 & 9.8 & $<0.001$ \\
\hline Anxiolytic treatment & 5.7 & 9.5 & 0.05 \\
\hline \multicolumn{4}{|l|}{ Questionnaire data } \\
\hline Anxiety score & $2.4 \pm 0.1$ & $3.9 \pm 0.2$ & $<0.001$ \\
\hline Depression score & $1.8 \pm 0.1$ & $3.0 \pm 0.2$ & $<0.001$ \\
\hline ESS score & $6.3 \pm 0.2$ & $5.1 \pm 0.2$ & NS \\
\hline
\end{tabular}

Data are presented as mean \pm SEM or $\%(n=641)$, unless otherwise indicated. BMI: body mass index; SBP: systolic blood pressure; DBP: diastolic blood pressure; ESS: Epworth Sleepiness Scale; NS: nonsignificant. \#: independentsamples t-test or Chi-squared test, as appropriate.

\begin{tabular}{|c|c|c|c|c|}
\hline \multirow[t]{3}{*}{ TABLE 2} & $\begin{array}{l}\text { nd anthrc } \\
\text { a/hypopr }\end{array}$ & $\begin{array}{l}\text { opometric } \\
\text { noea index }\end{array}$ & $\begin{array}{l}\text { data for the } \\
\times(\mathrm{AHI}) \text { anc }\end{array}$ & $\begin{array}{l}\text { e samples } \\
\text { d sex }\end{array}$ \\
\hline & \multicolumn{2}{|c|}{ AHI $<15$ events $\cdot h^{-1}$} & \multicolumn{2}{|c|}{ AHI $>15$ events $\cdot h^{-1}$} \\
\hline & Males & Females & Males & Females \\
\hline Subjects $n$ & 86 & 186 & 176 & 193 \\
\hline Age yrs & $68.5 \pm 0.08$ & $68.5 \pm 0.06$ & $68.6 \pm 0.06$ & $668.7 \pm 0.06$ \\
\hline $\mathrm{BMI} \mathbf{k g} \cdot \mathrm{m}^{-2}$ & $25.3 \pm 0.31$ & $24.2 \pm 0.30$ & $26.4 \pm 0.20$ & $25.5 \pm 0.30^{*}$ \\
\hline Ambulatory SBP mmHg & $119.8 \pm 1.5$ & $114.2 \pm 1.0$ & $122.0 \pm 1.0$ & $119.2 \pm 1.0^{\circ}$ \\
\hline Ambulatory DBP mmHg & $75.7 \pm 0.7$ & $71.9 \pm 0.5$ & $77.0 \pm 0.5$ & $75.8 \pm 0.6^{\bullet}$ \\
\hline \multicolumn{5}{|c|}{ Clinical data } \\
\hline Hypertension & 37.2 & 35.5 & $49.7^{\#}$ & $45.6^{\circ}$ \\
\hline Diabetes & 8.1 & 3.2 & 9.7 & $3.6^{\star}$ \\
\hline Dyslipidaemia & 27.9 & 37.6 & 30.3 & $39.4^{*}$ \\
\hline Smoker & 46.5 & $13.4^{\star \star *}$ & 42.9 & $22^{* \star *}$ \\
\hline Hypnotic treatment & 0 & 2.1 & 1.7 & 2.6 \\
\hline Antidepressant treatment & 2.3 & $10.2^{\star *}$ & 2.3 & $19.3^{* \star \cdot}$ \\
\hline Anxiolytic treatment & 10.5 & 8.1 & 9.4 & $10.9^{* \star \cdot}$ \\
\hline \multicolumn{5}{|l|}{ Questionnaire data } \\
\hline Anxiety score & $2.3 \pm 0.2$ & $3.9 \pm 0.2^{\star \star *}$ & $2.5 \pm 0.2$ & $4.0 \pm 0.2^{\star \star \star}$ \\
\hline Depression score & $1.5 \pm 0.2$ & $2.8 \pm 0.2^{* \star *}$ & $1.9 \pm 0.1$ & $3.2 \pm 0.2^{\star \star \star}$ \\
\hline ESS score & $5.7 \pm 0.4$ & $4.9 \pm 0.2$ & $6.7 \pm 0.3$ & $5.3 \pm 0.3$ \\
\hline $\begin{array}{l}\text { Positive Berlin } \\
\text { questionnaire }\end{array}$ & 20.9 & 19.9 & $42.1^{\# \#}$ & $37.8^{\%}$ \\
\hline
\end{tabular}

Data are presented as mean \pm SEM or $\%(n=641)$, unless otherwise indicated. BMI: body mass index; SBP: systolic blood pressure; DBP: diastolic blood pressure; ESS: Epworth Sleepiness Scale. $*: p \leqslant 0.05 ; * \star: p \leqslant 0.01$ ***: $p \leqslant 0.001$ versus males in same AHI group; $\#: p \leqslant 0.05 ; \#: p \leqslant 0.01$

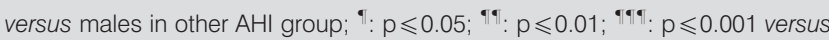
females in other AHI group (all one-way ANOVA with post hoc Scheffé test)

anxious $(p<0.05)$ and depressed $(p<0.001)$. Males with OSA were more frequently smokers and diabetic. HTN was more frequent in males than in females, but the difference did not reach significance.

Table 3 shows anthropometric, polygraphic and DEXA data in the OSA group by sex. Overall, males exhibited a greater BMI than females. In the overweight group (BMI of $>25 \mathrm{~kg} \cdot \mathrm{m}^{-2}$ ), males occurred proportionally more frequently $(67 \%)$, whereas, in the pathologically obese group (BMI of $>30 \mathrm{~kg} \cdot \mathrm{m}^{-2}$ ) females were proportionally higher (16\%). Females showed a lower NC and WC than males. Comparison of DEXA data by sex (table 3) revealed that, although CFM did not differ between sexes, females had a significantly higher PFM.

Polygraphic findings in males and females with OSA are reported in table 3. Females exhibited a less severe AHI, more hypopnoeas than apnoeas, and lower ODIs and times with an $\mathrm{Sa}_{1} \mathrm{O}_{2}$ of $<90 \%(\mathrm{p}<0.05)$. Only $16 \%$ of females had an $\mathrm{AHI}$ of $>30$ events $\cdot h^{-1}$. No differences in autonomic arousal index, reported sleep time $(6.8 \pm 0.1$ versus $6.7 \pm 0.1 \mathrm{~h}$ in males versus females) and mean $\mathrm{Sa}_{2} \mathrm{O}_{2}(95.0 \pm 0.1 \%$ in males and $95.3+0.1 \%$ in females) were found between males and females with OSA.

Overall, sleepiness was not frequently reported, the mean ESS score being 5.6. A total of 58 subjects, 40 males and 18 females, reported an ESS score of $\geqslant 10$. 


\begin{tabular}{|c|c|c|c|c|}
\hline \multirow[t]{2}{*}{ TABLE 3} & \multicolumn{4}{|c|}{$\begin{array}{l}\text { Anthropometric and body composition } \\
\text { measurements of obstructive sleep apnoea } \\
\text { subjects }^{\#} \text { by sex }\end{array}$} \\
\hline & & Males & Females & p-value \\
\hline \multicolumn{5}{|c|}{ Anthropometric measurements } \\
\hline $\mathrm{BMI} \mathrm{kg} \cdot \mathrm{m}^{-2}$ & & $26.4 \pm 0.2$ & $25.5 \pm 0.3$ & $<0.001$ \\
\hline $\mathrm{BMl}>25 \mathrm{kc}$ & $m^{-2}$ & 67.0 & 47.7 & $<0.001$ \\
\hline $\mathrm{BMI}>30 \mathrm{kc}$ & $m^{-2}$ & 11.0 & 15.5 & 0.005 \\
\hline $\mathrm{HC} \mathrm{cm}$ & & $99.1 \pm 0.5$ & $98.9 \pm 0.7$ & NS \\
\hline$W C \mathrm{~cm}$ & & $92.7 \pm 0.7$ & $84.0 \pm 0.8$ & 0.004 \\
\hline Waist/hip & & $0.93 \pm 0.005$ & $0.85 \pm 0.005$ & NS \\
\hline $\mathrm{NC} \mathrm{cm}$ & & $40.4 \pm 0.2$ & $34.9 \pm 0.2$ & $<0.001$ \\
\hline \multicolumn{5}{|c|}{ DEXA measurements } \\
\hline Body mass & & $78.5 \pm 8.6$ & $65.8 \pm 8.5$ & 0.01 \\
\hline BMC kg & & $2.49 \pm 2.7$ & $1.86 \pm 2.9$ & 0.01 \\
\hline Total lean $n$ & ass $\mathrm{kg}$ & $55.4 \pm 5.6$ & $39.5 \pm 5.2$ & 0.004 \\
\hline TFM kg & & $20.4 \pm 4.9$ & $24.5 \pm 0.6$ & 0.001 \\
\hline CFM kg & & $13.2 \pm 3.2$ & $13.1 \pm 3.1$ & NS \\
\hline CFM \% TFN & & 64.8 & 53.0 & 0.001 \\
\hline PFM kg & & $7.2 \pm 2.0$ & $11.6 \pm 4.0$ & $<0.001$ \\
\hline PFM \% TFN & & 35.5 & 47.0 & $<0.001$ \\
\hline \multicolumn{5}{|c|}{ Polygraphic study } \\
\hline Subjective & ST min & $6.80 \pm 0.1$ & $6.68 \pm 0.1$ & NS \\
\hline Respiratory & AAl events $\cdot h^{-1}$ & $22.0 \pm 0.9$ & $18.2 \pm 0.5$ & $<0.001$ \\
\hline Snoring ind & $x$ events $\cdot h^{-1}$ & $65.6 \pm 6.9$ & $75.8 \pm 6.8$ & NS \\
\hline AHI events. & & $36.1 \pm 1.4$ & $27.1 \pm 0.8$ & $<0.001$ \\
\hline ODI events & & $15.6 \pm 0.9$ & $10.8 \pm 0.5$ & $<0.001$ \\
\hline Mean $\mathrm{Sa}, \mathrm{O}_{2}$ & & $95.0 \pm 0.1$ & $95.3 \pm 0.1$ & NS \\
\hline Time $\mathrm{Sa}_{1} \mathrm{O}_{2}$ & $90 \% \min$ & $2.70 \pm 0.53$ & $1.95 \pm 0.13$ & 0.05 \\
\hline Minimal Sa, & $2 \%$ & $88.6 \pm 0.3$ & $89.9 \pm 0.3$ & NS \\
\hline
\end{tabular}

Data are presented as mean \pm SEM or \%, unless otherwise indicated. BMI: body mass index; HC: hip circumference; WC: waist circumference; NC: neck circumference; DEXA: dual-energy X-ray absorptiometry; BMC: bone mineral content; TFM: total fat mass; CFM: central fat mass; PFM: peripheral fat mass; TST: total sleep time; AAl: autonomic arousal index; AHI: apnoea/hypopnoea index; ODI: oxygen desaturation index; $\mathrm{Sa}_{1} \mathrm{O}_{2}$ : arterial oxygen saturation; NS: nonsignificant. ${ }^{\#}$ : AHI of $>15$ events $\cdot h^{-1}$; ${ }^{\bullet}$ independent-samples t-test.

\section{Differences between subjects with and without OSA}

Compared to the 186 females without OSA (table 2), females with OSA were more frequently positive at the Berlin questionnaire $(p<0.01)$ and more frequently reported HTN (45.6 versus $35.5 \% ; \mathrm{p}=0.04$ ), without differences for the other clinical data. When medication was considered, it was noted that females with OSA showed a greater intake of antidepressants and a trend towards increased use of anxiolytics. Considering anthropometric data, females with OSA exhibited a greater BMI $\left(25.6 \pm 0.3\right.$ versus $\left.24.2 \pm 0.3 \mathrm{~kg} \cdot \mathrm{m}^{-2} ; \mathrm{p}<0.01\right)$ and a greater NC $(34.9 \pm 0.2 \mathrm{~cm}$ with OSA versus $34.0 \pm 0.2 \mathrm{~cm}$ without OSA; $\mathrm{p}=0.02$ ), without differences for WC and HC (fig. 1a and b). Comparison of DEXA data did not show any significant differences among females with and without OSA, CFM, PFM and total fat mass being similar in both groups (fig. $1 \mathrm{a}$ and $\mathrm{b}$ ).

Comparison of males with and without OSA showed that males with OSA reported HTN more frequently than males without OSA, and scored more positively at the Berlin questionnaire. DEXA and anthropometric data (fig. 1c and d) did not show any significant differences between males with and without OSA, CFM being the only parameter showing a trend to a nonsignificant rise in males with OSA.

\section{Factors associated with OSA in females}

In order to examine the effect of clinical, anthropometric and DEXA parameters on OSA risk in females, multiple logistic regression analysis was employed. The final model was adjusted for BMI, NC, depression and anxiety scores, medication, history of HTN, dyslipidaemia and blood pressure. Sex was associated with HTN, females showing increased HTN risk (OR 1.52, 95\% CI 1.00-2.30; p=0.04) and increased 24-h systolic blood pressure (OR 1.03, 95\% CI 1.00-1.5; $\mathrm{p}=0.006$ ) compared to males.

\section{DISCUSSION}

To our knowledge, this is the first epidemiological study examining a large cohort of healthy elderly subjects and investigating the sex differences in clinical, anthropometric and risk factors in subjects having OSA. First, as expected, the sex differences in OSA decrease with age, the ratio of OSA risk being 1.31 in the present study population. Secondly, when clinical symptoms of OSA are considered, as in middle-aged studies, females reported the cardinal symptoms of OSA less frequently and had a higher risk of having had, or being treated for, mood and anxiety disorders. Although depression and anxiety scores were higher in females with OSA, comparison of females with and without OSA showed that there were no significant differences between groups for anxiety and depression scores, as well as for previous psychiatric treatment. Therefore, sex differences in personality characteristics [12, 30], more than the presence of OSA, contribute to clinical spectrum in females with OSA. Thirdly, females with OSA show increased risk of pathological obesity and greater peripheral obesity than males. However, comparison of females with and without OSA shows the lack of significant differences in anthropometrics and DEXA values, suggesting that obesity and fat distribution do not contribute to OSA risk in elderly females. Finally, analysis of factors associated with OSA shows that HTN and increased systolic blood pressure are the factors associated with the increased OSA risk in older females but not in males. This relationship should be replicated in a large clinical population in order to define whether or not the cardiovascular risk of OSA in the elderly is a specific sex effect.

The ratio of males to females with OSA in clinical studies appears to be considerably higher than in community studies $[4,10]$. The reason for this discrepancy is not clear, and misdiagnosis related to lack of specific clinical complaints has been postulated, depressive symptoms, benzodiazepine and antidepressant treatment, and tiredness being more commonly reported in females $[5,12]$. The major limitation of all studies conducted to date was that sample size was relatively small and the effects of confounding factors, such as age, were not carefully accounted for. In order to overcome some of the bias of previous studies, it was decided to analyse data collected from nearly 650 subjects drawn from a community-based cohort matched for age, one of the factors contributing most to 

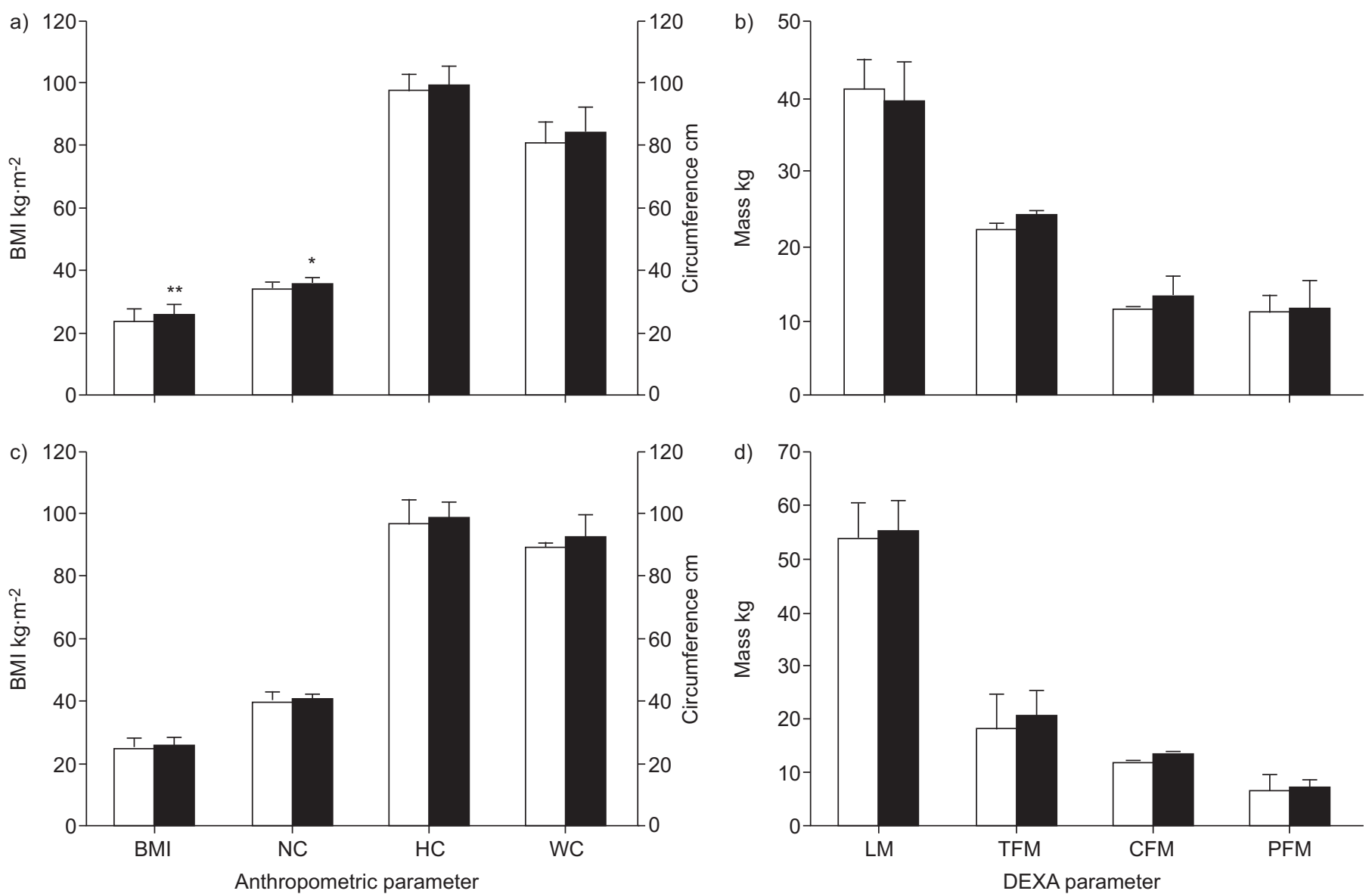

FIGURE 1. Histograms showing: $a, c)$ anthropometric; and b, d) dual-energy $X$-ray absorptiometry (DEXA) data in groups of: a, b) females; and c, d) males without and with obstructive sleep apnoea ( $\square$ : apnoea/hypopnoea index (AHI) of $<15$ events $\cdot h^{-1} ; \mathbf{a}$ : AHI of $>15$ events. $h^{-1}$ ). No significant differences in anthropometric and DEXA data were detected between groups. BMI: body mass index; NC: neck circumference; HC: hip circumference; WC: waist circumference; LM: lean mass; TFM: total fat mass; CFM: central fat mass; PFM: peripheral fat mass. *: $p<0.05 ;{ }^{*}$ : $p<0.01$ versus AHI of $<15$ events $\cdot h^{-1}$.

OSA risk in females. In the present population, the $\sim 1.3$ malefemale risk prevalence of OSA reflects ratios previously reported for community studies, underlying similarities between the present sample and other cohorts. Therefore, a greater OSA risk is present in the elderly in males and females equally, explaining the high cardiovascular morbidity, use of psychoactive medications and healthcare utilisation in older adults [31].

Consistent with previous studies $[2,4,10]$, sex differences were found in cardiovascular and metabolic risks, HTN and diabetes being reported more commonly in males (49.7 and $9.7 \%$, respectively) than in females (HTN $45.6 \%$ and diabetes $3.6 \%$ ). No significant difference in HTN was found between sexes. With regard to clinical symptoms, females reported snoring and apnoea less frequently, had higher depression and anxiety scores, and reported treatment for mood and anxiety disorders more frequently. The comparison of females with and without OSA, however, showed that none of these atypical symptoms differed significantly between groups, suggesting that they are more related to a sex phenotype in the psychological profile rather than the presence of OSA [12].

Among factors contributing to OSA in older females, ageing, body fat distribution [6] and hormonal influences [9] have been proposed. Since, in the present sample, all female cases were post-menopausal and did not report substitutive treatment, it was possible to examine the specific role of obesity and fat distribution in OSA occurrence. As is the case for middle-aged females $[11,15]$, the present females were more likely to be obese (BMI of $>30 \mathrm{~kg} \cdot \mathrm{m}^{-2}$ ) and to have a significantly higher percentage of their fat mass at the periphery. Even though these data are in line with previous reports in middle-aged patients $[6,15]$, the type of obesity did not completely explain the observed differences in the present population. The CFM did not differ significantly between males and females with OSA, and no significant differences in the anthropometric and DEXA data were observed between females with and without OSA. Therefore, it can be suggested that, in older subjects, the effects of obesity and fat distribution alone do not contribute greatly to the occurrence of the disease, increased collapsibility and ageing-related changes in the upper airway probably playing a major role $[32,33]$. Interestingly, it was found that females with OSA showed increased use of anxiolytics, medication that, increasing pharyngeal collapsibility, might explain the rise in OSA incidence in the present females.

When we attempted to explain which factors contributed to the occurrence of OSA in the present older females, it was found 
that HTN was the only one. Previous data on prevalence of HTN in an OSA population have reported controversial results, some authors reporting an equal risk in groups of males and females with OSA [34], with others showing an association between OSA and HTN almost entirely restricted to the male sex [14]. These differences may be explained by several factors, such as composition of groups, criteria for defining HTN and coexistence of traditional risk factors, such as obesity, diabetes, smoking and hyperlipidaemia. The present finding has clinical consequences, older females with OSA being at greater risk of HTN and cardiovascular diseases than females without OSA [34, 35]. This increased susceptibility to HTN in older females with OSA may be related to sex differences in endothelial dysfunction [36] or genetic predisposition [37] and susceptibility [38] to HTN, as suggested for middle-aged patients. Given that OSA is a risk factor for HTN in older females, powered studies examining sex differences in response to treatment are required in order to confirm this sex association.

In the interpretation of the present results, some limitations need to be considered. First, participants were recruited from a cross-sectional community-based population aged 68 yrs at study entry, from which subjects with previous medical, heart, neurological and cardiovascular diseases were excluded. In addition, the majority of the sample did not report the clinical symptoms of sleep-related breathing disorders, as is common in elderly patients [39]. Therefore, the age at study entry, exclusion criteria and lack of typical symptoms may limit the evaluation to the very healthy and the very young elderly, and the results cannot be extrapolated to clinic-based samples. Secondly, a high prevalence of OSA was found in the present sample, half of the subjects having an AHI of $>15$ events $\cdot h^{-1}$. An explanation for this high prevalence might be the use of ambulatory polygraphy, which may include respiratory events occurring during wakefulness, inducing overestimation of apnoeas and hypopnoeas. Despite this limitation, polygraphic monitoring has been applied in middle-aged and elderly population [40].

In conclusion, in an elderly community population, the incidence of undiagnosed OSA in females was similar to that found in males. The atypical clinical spectrum and fat distribution in females with OSA appears to be more sexrelated than OSA-dependent. The presence of OSA predisposed the present females to increased risk of HTN, stressing the need for increased awareness of the disease and prompt therapy in elderly female populations.

\section{SUPPORT STATEMENT}

This study was supported by a grant from the French Ministry of Health (Paris, France; Cellule Projet Hospitalier de Recherche Clinique National, Direction de la Recherche Clinique, Centre Hospitalier Universitaire de Saint-Etienne; Appel d'Offre 1998 and Appel d'Offre 2002), and by a grant a from L'Association de Recherche SYNAPSE (Saint-Etienne, France).

\section{CLINICAL TRIAL}

This study is registered at ClinicalTrials.gov (trial numbers NCT00759304 and NCT00766584).

\section{STATEMENT OF INTEREST}

None declared.

\section{REFERENCES}

1 Jennum P, Riha RL. Epidemiology of sleep apnoea/hypopnoea syndrome and sleep-disordered breathing. Eur Respir J 2009; 33: 907-914.

2 Kezirian EJ, Harrison SL, Ancoli-Israel S, et al. Behavioral correlates of sleep-disordered breathing in older women. Sleep 2007; 30: 1181-1188.

3 Mehra R, Stone KL, Blackwell T, et al. Prevalence and correlates of sleep-disordered breathing in older men: Osteoporotic Fractures in Men Sleep Study. J Am Geriatr Soc 2007; 55: 1356-1364.

4 Young T, Peppard PE, Gottlieb DJ. Epidemiology of obstructive sleep apnea: a population health perspective. Am J Respir Crit Care Med 2002; 165: 1217-1239.

5 Dancey DR, Hanly PJ, Soong C, et al. Gender differences in sleep apnea. Chest 2003; 123: 1544-1550.

6 Millman RP, Carlisle CC, McGarvey ST, et al. Body fat distribution and sleep apnea severity in women. Chest 1995; 107: 362-366.

7 Pillar G, Malhotra A, Fogel R, et al. Airway mechanics and ventilation in response to resistive loading during sleep: influence of gender. Am J Respir Crit Care Med 2000; 162: 1627-1632.

8 Schellenberg JB, Maislin G, Schwab RJ. Physical findings and the risk for obstructive sleep apnea. The importance of oropharyngeal structures. Am J Respir Crit Care Med 2000; 162: 740-748.

9 Dancey DR, Hanly PJ, Soong C, et al. Impact of menopause on the prevalence and severity of sleep apnea. Chest 2001; 120: 151-155.

10 Tishler PV, Larkin EK, Schluchter MD, et al. Incidence of sleepdisordered breathing in an urban adult population: the relative importance of risk factors in the development of sleep-disordered breathing. JAMA 2003; 289: 2230-2237.

11 Bixler EO, Vgontzas AN, Lin HM, et al. Prevalence of sleepdisordered breathing in women: effects of gender. Am J Respir Crit Care Med 2001; 163: 608-613.

12 Young T, Hutton R, Finn L, et al. The gender bias in sleep apnea diagnosis. Are women missed because they have different symptoms? Arch Intern Med 1996; 156: 2445-2551.

13 O'Connor C, Thornley KS, Hanly PJ. Gender differences in the polysomnographic features of obstructive sleep apnea. Am J Respir Crit Care Med 2000; 161: 1465-1472.

14 Hedner J, Bengtsson-Bostrom K, Peker Y, et al. Hypertension prevalence in obstructive sleep apnoea and sex: a populationbased case-control study. Eur Respir J 2006; 27: 564-570.

15 Jordan AS, McEvoy RD. Gender differences in sleep apnea: epidemiology, clinical presentation and pathogenic mechanisms. Sleep Med Rev 2003; 7: 377-389.

16 Yukawa K, Inoue Y, Yagyu H, et al. Gender differences in the clinical characteristics among Japanese patients with obstructive sleep apnea syndrome. Chest 2009; 135: 337-343.

17 Young T. Sleep-disordered breathing in older adults: is it a condition distinct from that in middle-aged adults? Sleep 1996; 19: 529-530.

18 Ancoli-Israel S, Coy T. Are breathing disturbances in elderly equivalent to sleep apnea syndrome? Sleep 1994; 17: 77-83.

19 Greenberg-Dotan S, Reuveni H, Simon-Tuval T, et al. Gender differences in morbidity and health care utilization among adult obstructive sleep apnea patients. Sleep 2007; 30: 1173-1180.

20 Lin CM, Davidson TM, Ancoli-Israel S. Gender differences in obstructive sleep apnea and treatment implications. Sleep Med Rev 2008; 12: 481-496.

21 Barthélémy JC, Pichot V, Dauphinot V, et al. Autonomic nervous system activity and decline as prognostic indicators of cardiovascular and cerebrovascular events: the PROOF study. Study design and population sample. Associations with sleep-related breathing disorders: the 'SYNAPSE' study. Neuroepidemiology 2007; 29: 18-28.

22 Salamone LM, Fuerst T, Visser M, et al. Measurement of fat mass using DEXA: a validation study in elderly adults. J Appl Physiol 2000; 89: 345-352. 
23 Pichot P, Brun JP. Brief self-evaluation questionnaire for depressive, asthenic and anxious dimensions. Ann Med Psychol 1984; 142: 862-865.

24 Goldberg D, Bridges K, Duncan-Jones P, et al. Detecting anxiety and depression in general medical settings. BMJ 1988; 297: 897-899.

25 Johns MW. A new method for measuring daytime sleepiness: the Epworth Sleepiness Scale. Sleep 1991; 14: 540-545.

26 Netzer NC, Stoohs RA, Netzer CM, et al. Using the Berlin questionnaire to identify patients at risk for the sleep apnea syndrome. Ann Intern Med 1999; 131: 485-491.

27 Collop NA, Anderson WM, Boehlecke B, et al. Clinical guidelines for the use of unattended portable monitors in the diagnosis of obstructive sleep apnea in adult patients. J Clin Sleep Med 2007; 3: 737-747.

28 Pitson DJ, Stradling JR. Autonomic markers of arousal during sleep in patients undergoing investigation for obstructive sleep apnoea: their relationship to EEG arousals, respiratory events and subjective sleepiness. J Sleep Res 1998; 7: 53-59.

29 Mant A, Saunders NA, Eyland EA, et al. Sleep habits and sleep related respiratory disturbance in an older population. In: Horne J, ed. Sleep '88. Stuttgart, Gustav Fischer Verlag, 1989; pp. 260-261.

30 Ye L, Pien GW, Weaver TE. Gender differences in the clinical manifestation of obstructive sleep apnea. Sleep Med 2009; 10: 1075-1084.

31 Tarasiuk A, Greenberg-Dotan S, Simon-Tuval T, et al. The effect of obstructive sleep apnoea on morbidity and health care utilization of middle-aged and older adults. J Am Geriatr Soc 2008; 56: 247-254.
32 Ray AD, Ogasa T, Magalang UJ, et al. Aging increases upper airways collapsibility in Fisher 344 rats. J Appl Physiol 2008; 105: 1471-1476.

33 Eikermann M, Jordan AS, Chamberlin NL, et al. The influence of aging on pharyngeal collapsibility during sleep. Chest 2007; 131: 1702-1709.

34 Nieto FJ, Young TB, Lind BK, et al. Association of sleep disordered breathing, sleep apnea, and hypertension in a large communitybased study. JAMA 2000; 283: 1829-1836.

35 Laaban JP, Mounier L, Roque d'Orbcastel O, et al. Cardiovascular risk factors in men and women with obstructive sleep apnoea syndrome. Respir Med 2010; 104: 1063-1068.

36 Faulx MD, Larkin EK, Hoit BD, et al. Sex influences endothelial function in sleep-disordered breathing. Sleep 2004; 27: 1113-1120.

37 Drager LF, Pereira AC, Barreto-Filho JA, et al. Phenotypic characteristics associated with hypertension in patients with obstructive sleep apnea. J Hum Hypertens 2006; 20: 523-528.

38 Mohsenin V, Yaggi HK, Shah N, et al. The effect of gender on the prevalence of hypertension in obstructive sleep apnea. Sleep Med 2009; 10: 759-762.

39 Launois SH, Pepin JL, Levy P. Sleep apnea in the elderly: a specific entity? Sleep Med Rev 2007; 11: 87-97.

40 Johansson P, Alehagen U, Svanborg E, et al. Sleep disordered breathing in an elderly community-living population: relationship to cardiac function, insomnia symptoms and daytime sleepiness. Sleep Med 2009; 10: 1005-1011. 